\title{
Gender differences in coronary heart disease
}

\author{
A.H.E.M. Maas, Y.E.A. Appelman
}

Cardiovascular disease develops 7 to 10 years later in women than in men and is still the major cause of death in women. The risk of heart disease in women is often underestimated due to the misperception that females are 'protected' against cardiovascular disease. The under-recognition of heart disease and differences in clinical presentation in women lead to less aggressive treatment strategies and a lower representation of women in clinical trials. Furthermore, self-awareness in women and identification of their cardiovascular risk factors needs more attention, which should result in a better prevention of cardiovascular events. In this review we summarise the major issues that are important in the diagnosis and treatment of coronary heart disease in women. (Neth Heart J 2010;18:598-603.)

Keywords: Coronary Heart Disease; Gender Differences; Menopause; Women; Risk Factors

C ardiovascular disease develops 7 to 10 years later in women than in men and is still the major cause of death in women over the age of 65 years. The risk of heart disease in women is often underestimated due to the misperception that females are 'protected' against cardiovascular disease. Recent data from the National Health and Nutrition Examination Surveys (NHANES) have shown that over the past two decades the prevalence of myocardial infarctions has increased in midlife $(35$ to 54 years) women, while declining in similarly aged men. ${ }^{1}$ In a report from the European Heart

\author{
A.H.E.M. Maas \\ Isala Clinics, Zwolle, the Netherlands \\ Y.E.A. Appelman \\ VU Medical Center, Amsterdam, the Netherlands \\ Correspondence to: A.H.E.M. Maas \\ Department of Cardiology, Isala Clinics, PO Box 10400 , \\ 8000 GK Zwolle, the Netherlands \\ E-mail: a.maas@diagram-zwolle.nl
}

Survey on stable angina pectoris it was found that women are less likely to be referred for functional testing for ischaemia and that a lower rate of diagnostic angiograms and interventional procedures are performed compared with men. ${ }^{2}$ The underrecognition of heart disease and differences in clinical presentation in women lead to less aggressive treatment strategies and a lower representation of women in clinical trials. Furthermore, self awareness in women and identification of their cardiovascular risk factors needs more attention which should result in a better prevention of cardiovascular events. In this review we summarise the major issues that are important in the diagnosis and treatment of coronary heart disease (CHD) in women.

\section{Epidemiology and role of menopause}

It is assumed that exposure to endogenous oestrogens during the fertile period of life delays the manifestation of atherosclerotic disease in women. Before menopause the CHD event rate in women is low and predominantly attributed to smoking. ${ }^{3}$ Women with an early menopause ( $<40$ years) have a two-year lower life expectancy compared with women with a normal or late menopause. ${ }^{4}$ Data from the Framingham Heart Study suggest that a harmful cardiovascular risk profile may be more cause than consequence of age at menopause. In the Women's Ischemia Syndrome Evaluation (WISE) study it was shown that young women with endogenous oestrogen deficiency have a more than sevenfold increase in coronary artery risk. ${ }^{5}$ Oestrogens have a regulating effect on several metabolic factors, such as lipids, inflammatory markers and the coagulant system. They also promote a direct vasodilatory effect through the $\alpha$ and $\beta$ receptors in the vessel wall. Furthermore, signs of subclinical atherosclerosis, as visualised by intima-media thickness measurements, can already be found in women before menopause, especially when several CHD risk factors are present. ${ }^{6}$ Flow-mediated vasoreactivity by brachial artery measurements declines with the time elapsed since menopause. After menopause atherosclerotic plaque composition 
changes into more vulnerable lesions with inflammatory factors involved.

\section{Gender differences in major CHD risk factors}

Menopause transition is associated with a worsening $\mathrm{CHD}$ risk profile. ${ }^{7}$

Women with clinically manifest CHD are in general older than men, with a higher expression of cardiovascular risk factors. ${ }^{8,9}$ Although women and men share most classic risk factors, the significance and the relative weighting of these factors are different. At younger ages ( $<50$ years) smoking is more deleterious in women than in men, with a larger negative impact of the total number of cigarettes smoked per day. ${ }^{3,10}$ Smoking increases the risk of a first acute myocardial infarction (AMI) relatively more in females than in men. In young premenopausal women smoking causes a downregulation of the oestrogen-dependent vasodilatation of the endothelial wall. ${ }^{11}$ Whether smoking reduces age at menopause remains a matter of debate.

Body weight may increase during the first years since menopause and body fat distribution changes from a gynoid to a more android pattern. Central obesity with an increase in visceral fat occurs more frequently after menopause, with a higher presence of comorbid risk factors and components of the metabolic syndrome in women compared with ageing men. ${ }^{12}$ With the increasing incidence of obesity there is a parallel increase in the prevalence of type 2 diabetes. Women with diabetes are at greater risk for cardiovascular complications than their male counterparts. In a meta-analysis of 37 prospective cohort studies, the risk of fatal CHD is $50 \%$ higher in women with diabetes compared with male diabetics. ${ }^{13}$ The reason for this higher mortality is multifactorial and related to a heavier risk factor burden, more involvement of inflammatory factors, smaller vessel size of the coronary arteries and an often less aggressive treatment of diabetes in women.

Systolic blood pressure rises more steeply in ageing women compared with men, and this may be related to the decline in oestrogen levels in menopause transition. ${ }^{14-16}$ After menopause there is an upregulation of the renin-angiotensin system, with an increase in plasma-renin activity. Salt sensitivity and sympathetic activity are also increased in postmenopausal compared with premenopausal women. At older age (>75 years) isolated systolic hypertension is $14 \%$ more prevalent in women and an important cause of left ventricular hypertrophy, (diastolic) heart failure and strokes. Moderate or borderline hypertension $(<140 / 90 \mathrm{mmHg})$ causes more endothelial dysfunction and cardiovascular complications in women than in men. ${ }^{17}$ Hypertension often starts in the menopausal transition period and can cause a variety of complaints, such as chest pain, pal- pitations, headaches and even sensations of hot flashes. ${ }^{18}$ These complaints are often attributed to menopause but are less prevalent when elevated blood pressure is adequately treated. ${ }^{19}$ It is controversial whether women who have relatively more vasomotor symptoms during menopause transition are at greater risk for $\mathrm{CHD} .{ }^{20}$

At younger age, the relative risk of hypercholesterolaemia is lower in women compared with men. During menopause, total cholesterol and low-density lipoprotein (LDL) levels rise by 10 and $14 \%$ respectively and lipoprotein (a) increases 4 to $8 \%$, whereas high-density lipoprotein (HDL) cholesterol levels remain unchanged. ${ }^{7,21}$ It may therefore be important to (re)evaluate the lipid profile after menopause when borderline premenopausal values were found. Above 65 years of age mean LDL cholesterol is higher in women compared with men. At all ages HDL-cholesterol levels are 0.26 to 0.36 $\mathrm{mmol} / \mathrm{l}$ higher in women but from the Framingham study it is known that a low HDL cholesterol implicates a higher CHD risk in women than in men. ${ }^{22}$ Although women have often been underrepresented in many statin trials in the past, there is currently no doubt that in secondary prevention LDL reduction in women leads to an equally lower CHD mortality as in men. ${ }^{23}$ On the other hand, in primary prevention the role of statin therapy in women is still controversial. Caution is needed, however, as women have a lower absolute risk in the age groups that have been studied thus far. A recent large Japanese study showed clear benefits of primary prevention with statins in women with moderately elevated cholesterol levels above the age of 55 years. ${ }^{24}$ The age difference in the occurrence of CHD events among men and women was accounted for in the JUPITER trial, where comparable benefits of primary prevention with a statin were found in healthy men $\geq 50$ years and in women $\geq 60$ years with normal LDL levels but elevated hs-CRP levels. ${ }^{25}$

\section{Female-specific risk factors}

Although studies have shown that hormonal dysfunction in premenopausal women is associated with an increased risk of atherosclerosis and CHD events, it is still unclear whether the polycystic ovary syndrome (PCOS) is an independent risk factor for atherosclerosis. ${ }^{5,26}$ PCOS occurs in 8 to $10 \%$ of women and is an important cause of infertility. Women with this syndrome are at increased risk for development of the metabolic syndrome and type 2 diabetes mellitus. The difficulty in studying cardiovascular events in women with PCOS is due to the low prevalence of these events in premenopausal women. A greater clustering of CHD risk factors and an adverse CHD event rate was found in postmenopausal participants with PCOS within the WISE study population. ${ }^{27}$ 
Women with a history of hypertensive diseases in pregnancy are at increased risk for hypertension and premature cardiovascular disease later in life. Especially in women after preeclampsia, defined as hypertension $(\geq 140 / 90 \mathrm{mmHg})$ and proteinuria $(\geq 0.3 \mathrm{~g} / 24 \mathrm{~h})$ after 20 weeks of gestation, the risk of future CHD is twice as high compared with women who were normotensive during pregnancy. ${ }^{28}$ Women with a placental syndrome in combination with poor foetal growth or intrauterine death are considered to be at greatest risk. ${ }^{29}$ Hypertensive disorders are thought to be associated with an abnormal placentation leading to aberrant autonomic control and inappropriate release of vasoactive substances causing endothelial dysfunction in the maternal and foetal circulation. In women with gestational diabetes the relative risk to develop type 2 diabetes is even 7 to 12 times higher compared with women with normoglycaemic pregnancies. ${ }^{30}$ The characteristics of pregnancy-related disorders provide a unique opportunity for a better cardiovascular risk assessment and prevention, but have not yet been incorporated in the latest guidelines for CHD prevention in women. ${ }^{31}$

\section{Clinical presentation and noninvasive testing for angina pectoris}

The clinical presentation of coronary artery disease and the interpretation of noninvasive diagnostic testing is less reliable in women compared with men, especially in the age group below 55 years when the prevalence of coronary artery disease is still relatively low. ${ }^{32-34}$ Chest pain syndromes are more common in women than in men and are less related to the presence of atherosclerosis in the large epicardial coronary arteries. ${ }^{8,35-37}$ In addition, many causes of noncardiac chest pain can mimic the discomfort that is associated with myocardial ischaemia. Women who are diagnosed with noncardiac chest pain have a twofold increased risk to develop a CHD event in the next five to seven years and have a four times higher risk for re-hospitalisations and recurrent angiograms in the next 180 days. ${ }^{38,39}$ This implicates that traditional diagnostic methods are not optimal for women and that they should be treated more aggressively for their risk factors.

There are no gender-specific criteria for the interpretation of ECGs, although women have a higher heart rate at rest with a longer QT interval. Nonspecific ECG changes at rest, a lower exercise capacity and a smaller vessel size contribute to the lower sensitivity and specificity of noninvasive testing in women. ${ }^{33}$ At younger ages, endogenous oestrogen levels can induce ECG changes mimicking ischaemia. Female-specific normograms have been developed for treadmill exercise testing. A low exercise capacity in symptomatic as well as in asymptomatic women is a strong predictor of five-year mortality. Diagnostic accuracy of exercise testing in women can be further improved by assessment of the angina history, oestrogen status and the presence of major CHD risk factors. ${ }^{40}$

Stress echocardiography with exercise or dobutamine can be an important test to evaluate wall motion abnormalities and its clinical value is not different between the two genders. The accuracy of myocardial perfusion imaging scans used to be less in women in the past due to smaller vessel size and breast attenuation, but with more advanced SPECT imaging techniques performed with Technetium sestamibi the predictive value of the scans has improved dramatically. ${ }^{33}$ It remains important, however, to include signs of chest pain, electrocardiographic abnormalities and a low functional capacity in the interpretation of the scans. Microvascular dysfunction and diffuse coronary atherosclerosis without obstructive lesions is more prevalent in women than in men and can be better visualised with positron emission tomography (PET) and cardiovascular magnetic resonance (CMR) techniques. ${ }^{37,41}$ The relative low availability of these imaging modalities may be an important factor in the under-recognition of these syndromes in women. Calcium scoring with EBTC or multi-slice CT is a very useful modality to rule out the presence of obstructive $\mathrm{CHD}$, but the (cumulative) radiation exposure makes this technique less suitable in premenopausal women and for follow-up purposes. In women $>50$ years of age who are at intermediate risk for CHD the absence of coronary calcium has a very high $(99 \%)$ negative predictive value for obstructive coronary atherosclerosis. In all age groups calcium scores are lower in women than in men. ${ }^{42}$ Also, the use of coronary computed tomographic angiography (CCTA) at the emergency department is promising as a highly sensitive diagnostic tool in the early triage of women $<65$ years who present with symptoms of acute chest pain, but this technique has comparable limitations due to radiation exposure. ${ }^{37}$

\section{Acute coronary syndromes in women}

Many analyses of sex-based differences following acute coronary syndromes (ACS) have revealed conflicting results. At presentation in STEMI, both men and women have comparable symptoms of chest pain, but women tend to have more concomitant vaso-vegetative symptoms that can mask the chest pain, with less extensive ST-T elevations at admission especially at younger ages..$^{8,43,44}$ In women below 55 years of age unstable angina pectoris and non-STEMI are often misdiagnosed at the emergency department. ${ }^{45}$ Women with ACS are generally older with more clustering of risk factors that may contribute to their higher risk of mortality. $8,9,46$ Gender bias in treatment and gender disparities in vascular flow and structure may further add to this increased mortality. An interesting observation is that women with ACS have less extensive obstruc- 
tive and more diffuse coronary artery disease compared with men, but the event rate in nonobstructive coronary artery disease seems to be higher in women. ${ }^{8,37,47}$ In a recent large meta-analysis of 11 randomised ACS trials it was shown that sex-based differences in 30-day mortality among patients with various manifestations of ACS are largely explained by clinical differences at presentation and the severity of angiographically documented disease. ${ }^{48}$ Other aspects that may account for differences in outcomes between women and men are related to vascular biological factors such as a smaller atheroma burden and slower progression in women, a smaller vessel size, less collateral flow, lower coronary flow reserve, more vascular stiffness, differences in remodelling, and functional differences of smooth muscle cells in the vessel wall. ${ }^{35,37,47}$ While in STEMI both genders have equal benefit of early percutaneous coronary interventions (PCI), there is abundant evidence that in non-STEMI the therapeutic strategies should be different between men and women. ${ }^{47,49}$ In the FRISC II and RITA 3 trials, early invasive strategy of patients with unstable angina or non-STEMI ACS was proven to reduce mortality in men, but not in women. A meta-analysis of eight combined nonSTEMI trials has confirmed that an early conservative strategy in low-risk (biomarker-negative) women is better than an early invasive strategy, which is in line with the already updated ACC/AHA guidelines on non-STEMI in 2007..$^{\circ}$

Mortality after coronary artery bypass surgery $(\mathrm{CABG})$ is higher in women compared with men and this difference is more pronounced in the younger age groups, after adjustment for risk factors. ${ }^{51}$ Many factors influence this gender gap, such as comorbid conditions at older age, smaller vessel size, more urgent procedures in women and the presence of hypertensive heart disease. Furthermore, after PCI women have significantly more bleeding complications, especially when glycoprotein IIb/IIIa inhibitors are used. ${ }^{52}$ In a metaanalysis of various large ACS trials, no differences were found in the efficacy and safety of clopidogrel between men and women. ${ }^{53}$

\section{Chest pain with 'normal' coronary angiograms}

At younger ages women more often have ACS with angiographically 'normal' coronary arteries than men. ${ }^{8,47}$ The underlying mechanisms of this so-called coronary microvascular dysfunction are diverse and may be related to endothelial reactivity, low endogenous oestrogen levels, coagulation disorders, abnormal inflammatory reactions and its manifestation can have a substantial variability among individuals. ${ }^{37}$ Abnormal cardiac nociception can further attribute to persistent chest pain due to an increased coronary pain perception in women. ${ }^{54}$ When symptoms of microvascular dysfunction result in objective signs of ischaemia it is proposed to call this syndrome microvascular angina pectoris. The relationship between microvascular dysfunction and epicardial atherosclerosis is not yet fully understood. The prognosis of this syndrome is less beneficial than initially considered and often leads to recurrent hospitalisations and repeated coronary angiograms. ${ }^{39,55}$ The prognosis is worse in women with various risk factors and these should be treated aggressively to prevent future CHD events.

\section{Conclusion}

Cardiovascular disease is the major cause of death in women and is still under-recognised and undertreated. A greater awareness of the differences in presentation of angina pectoris and ACS between men and women, with gender-based interpretation of diagnostic tests, is mandatory for health care professionals to improve therapeutic strategies and outcomes in women. Cardiology guidelines should be more focused on sex-related differences when appropriate. Further, women themselves need to be more aware of their own risk factors and clinical signs of CHD. Many biological differences in atherosclerosis between men and women are not yet clarified and will need further research in the future.

\section{References}

1 Towfighi A, Zheng L, Ovbiagele B. Sex-specific trends in midlife coronary heart disease risk and prevalence. Arch Intern Med. 2009;169:1762-6.

2 Daly CA, Clemens F, Sendon JL, et al. The clinical characteristics and investigations planned in patients with stable angina presenting to cardiologists in Europe: from the Euro Heart Survey of Stable Angina. Eur Heart J. 2005;26:996-1010.

3 Prescott E, Hippe M, Schnohr P, Hein HO, Vestbo J. Smoking and risk of myocardial infarction in women and men: longitudinal population study. BMJ. 1998; 316:1043-7.

4 Ossewaarde ME, Bots ML, Verbeek AL, et al. Age at menopause, cause-specific mortality and total life expectancy. Epidemiology. 2005;16:556-62.

5 Bairey Merz CN, Johnson BD, Sharaf BL, et al. Hypoestrogenemia of hypothalamic origin and coronary artery disease in premenopausal women: a report from the NHLBI-sponsored WISE study. J Am Coll Cardiol. 2003;41:413-9

6 Sutton-Tyrell K, Lassila HC, Meilahn E, Bunker C, Matthews KA, Kuller LH. Carotid atherosclerosis in premenopausal and postmenopausal women and its association with risk factors measured after menopause. Stroke. 1998;29:1116-21

7 Matthews KA, Meilahn EN, Kuller LH, Kelsey SF, Caggiula AW, Wing RR. Menopause and risk factors for coronary heart disease. N Engl J Med. 1989;321:641-6.

8 Hochman JS, Tamis, JE, Thompson TD, et al. Sex, clinical presentation, and outcome in patients with acute coronary syndromes. N Engl J Med. 1999;341:226-32.

9 Vaccarino V, Parsons L, Every NR, Barron HV, Krumholz HM Sex-based differences in early mortality after myocardial infarction. National Registry of Myocardial Infarction 2 Participants. N Engl J Med. 1999;341:217-25.

10 Grundtvig M, Hagen TP, German M, Reikvam A. Sex-based differences in premature first myocardial infarction caused by smoking: twice as many years lost by women as by men. Eur J Cardiovasc Prev Rehab. 2009;16:174-9.

11 Vanhoutte PM, Shimokawa H, Tang EHC, Feletou M. Endothelial dysfunction and vascular disease. Acta Physiol. 2009;196:193-222.

12 Kip KE, Marroquin OC, Kelley DE, et al. Clinical importance of obesity versus the metabolic syndrome in cardiovascular risk in women. Circulation. 2004;109:706-13. 
13 Huxley R, Barzi F, Woodward M. Excess risk of fatal coronary heart disease associated with diabetes in men and women: metaanalysis of 37 prospective cohort studies. BMJ. 2006;332:73-8.

14 Burt VL, Whelton P, Roccella EJ, Brown C, Cutler JA, Higgins $\mathrm{M}$, et al. Prevalence of hypertension in the US adult population. Results from the Third National Health and Nutrition Examination Survey, 1988-1991. Hypertension. 1995;25:305-13

15 Dubey RK, Oparil S, Imthurn B, Jackson EK. Sex hormones and hypertension. Cardiovasc Res. 2002;53:688-708.

16 Barton M, Meyer MR. Postmenopausal hypertension. Mechanisms and therapy. Hypertension. 2009; 54:1118.

17 Vasan RS, Larson MG, Leip EP, Evans JC, O'Donnell CJ, Kannel WB, et al. Impact of high-normal blood pressure on the risk of cardiovascular disease. N Engl J Med. 2001;345:1291-7.

18 Maas AHEM, Franke HR. Women's health in menopause with a focus on hypertension. Neth Heart J. 2009;17:69-73.

19 Ikeda H, Inoue T, Uemura S, Kaibara R, Tanaka H, Node K. Effects of candesartan for middle-aged and elderly women with hypertension and menopausal-like symptoms. Hypertens Res. 2006;29:1007-12

20 Gast G-CM, Grobbee DE, Pop VJM, Keyzer JJ, Wijnandsvan Gent CJM, Samsioe GN, et al. Menopausal complaints are associated with cardiovascular risk factors. Hypertension. 2008;51:1492-8.

21 Abbey M, Owen A, Suzakawa M, Roach P, Nestel PJ. Effects of menopause and hormone replacement therapy on plasma lipids, lipoproteins and LDL-receptor activity. Maturitas. 1999;33:259-69.

22 Kannel WB, Castelli WP, Gordon T, McNamar PM. Serum cholesterol, lipoproteins, and the risk of coronary heart disease. The Framingham Study. Ann Intern Med. 1971;74:1-12

23 Baigent C, Keech A, Kearny PM, Blackwell L, Buck G, Pollicino C, et al. Cholesterol Treatment Trialists collaborators. Efficacy and safety of cholesterol-lowering treatment: prospective meta-analysis of data from 90.056 participants in 14 randomised trials of statins. Lancet. 2005;366:1267-78.

24 Mizuno K, Nakaya N, Ohashi Y, Tajima N, Kushiro T, Teramoto $\mathrm{T}$, et al. Usefulness of pravastatin in primary prevention of cardiovascular events in women. Analysis of the management of elevated cholesterol in the primary prevention group of adult Japanese (MEGA-study). Circulation. 2008;117:494-502.

25 Ridker PM, Danielson E, Fonseca FA, Genest J, Gotto AM, Kastelein JJ, et al. Rosuvastatin to prevent vascular events in men and women with elevated C-reactive protein. N Engl J Med. 2008;359:2195-207.

26 Setji TL, Brown AJ. Polycystic Ovary Syndrome: diagnosis and treatment. Am J Med. 2007; 120:128-32.

27 Shaw LJ, Bairey Merz N, Azziz R, Stanczyk FZ, Sopko G, Braunstein GD, et al. Postmenopausal women with a history of irregular menses and elevated androgen measurements at high risk for worsening cardiovascular event-free survival: results from the National Institutes of Health-NHLBI sponsored Women's Ischemia Syndrome Evaluation. J Clin Endocrinol Metab. 2008;93:1276-84.

28 Bellamy L, Casas JP, Hingorani AD, Williams DJ. Pre-eclampsia and risk of cardiovascular disease and cancer later in life: systematic review and meta-analysis. BMJ. 2007;335:974-85.

29 McDonald SD, Malinowski A, Zhou Q, Yusuf S, Devereaux PJ. Cardiovascular sequelae of preeclampsia/eclampsia: a systematic review and meta-analysis. Am Heart J. 2008;156:918-30.

30 Bellamy L, Casas JP, Hingorani AD, Williams D. Type 2 diabetes mellitus after gestational diabetes: a systematic review and meta-analysis. Lancet. 2009;373:1773-9.

31 Mosca L, Banka CL, Benjamin EJ, et al. Evidence-based guidelines for cardiovascular disease prevention in women: 2007 update. Circulation. 2007;115:1481-501

32 Douglas PS, Ginsburg GS. The evaluation of chest pain in women. N Engl J Med. 1996;334:1311-5.

33 Mieres JH, Shaw LJ, Arai A, Budoff MJ, Flamm SD, Hundley $\mathrm{G}$, et al. Role of non-invasive testing in the clinical evaluation of women with suspected coronary artery disease. Circulation. 2005;111:682-96.

34 Johnson BD, Kelsey SF, Bairey Merz CN. Clinical risk assessment in women: chest discomfort. Report from the WISE study. In: Shaw LJ, Redberg RF editors. CAD in women: evidence-based diagnosis and treatment. Totowa, NJ. Humana Press, 2003:129-42.
35 Pepine CJ, Kerensky RA, Lambert CR, Smith KM, von Me ring GO, Sopko G, et al. Some thoughts on the vasculopathy of women with ischemic heart disease. J Am Coll Cardiol 2006;47(suppl): S30-S35

36 Hemingway H, Langenberg C, Damant J, Frost C, Pyörälä K, Barrett-Connor E. Prevalence of angina in women versus men. A systematic review and meta-analysis of international variations across 31 countries. Circulation. 2008; 117:1526-36.

37 Shaw LJ, Bugiardini R, Bairey Merz CN. Women and ischemic heart disease. J Am Coll Cardiol. 2009;54:1561-75.

38 Robinson JG, Wallace R, Limacher M, Ren H, Cochrane B, Wassertheil-Smoller S, et al. Cardiovascular risk in women with non-specific chest pain (from the Women's Health Initiative hormone trials). Am J Cardiol. 2008;102:693-9.

39 Humphries KH, Pu A, Gao M, Carere RG, Pilote L. Angina with "normal" coronary arteries: sex differences in outcome. Am Heart J. 2008;155:375-81.

40 Morise AP, Olson MB, Bairey Merz NC, Mankad S, Rogers WJ, Pepine CJ, et al. Validation of the accuracy of pretest and exercise test scores in women with a low prevalence of coronary disease: the NHLB sponsored Women's Ischemia Syndrome Evaluation (WISE) study. Am Heart J. 2004;147:1085-92.

41 Reis SE, Holubkov R, Conrad Smith AJ, Kelsey SF, Sharaf BL, Reichek N, et al. Coronary microvascular dysfunction is highly prevalent in women with chest pain in the absence of coronary artery disease: results from the NHLBI WISE study. Am Heart J. 2001;141:735-41.

42 Raggi P, Gongora MC, Gopal A, Callister TQ, Budoff M, Shaw LJ. Coronary artery calcium to predict all cause mortality in elderly men and women. J Am Coll Cardiol. 2008;52:17-23.

43 Milner KA, Funk M, Richards S, Wilmes RM, Vaccarino V, Krumholz HM. Gender differences in symptom presentation associated with coronary heart disease. Am J Cardiol. 1999;84:396-9.

44 Dey S, Flather MD, Devlin G, Brieger D, Gurfunkel EP, Steg PG, et al Sex-related differences in the presentation, treatment and outcomes among patients with acute coronary syndromes: the Global Registry of Acute Coronary Events. Heart. 2009;95:20-6.

45 Pope JH, Aufderheide TP, Ruthazer R, Woolard RH, Feldman JA, Beshansky JR, et al. Missed Diagnoses of Acute Cardiac Ischemia in the Emergency Department. N Engl J Med. 2000;342:1163-70.

46 Milcent C, Dormont B, Durand-Zaleski I, Steg PG. Gender differences in hospital mortality and use of percutaneous coronary intervention in acute myocardial infarction. Circulation. 2007; 115:833-9.

47 Jacobs AK. Coronary intervention in 2009. Are women no different than men? Circ Cardiovasc Intervent. 2009;2:69-78.

48 Berger JS, Elliott L, Gallup D, Roe M, Granger CB, Armstrong PW, et al. Sex differences in mortality following acute coronary syndromes. JAMA. 2009;302:874-82.

49 Clayton TC, Pocock SJ, Henderson RA, Poole-Wilson PA, Shaw TR, Knight R, et al. Do men benefit more than women from an interventional strategy in patients with unstable angina or non-ST-elevation myocardial infarction? The impact of gen der in the RITA3 trial. Eur Heart J. 2004;25:1641-50.

50 Donoghue MO, Boden W, Braunwald E, Cannon CP, Clayton TC, de Winter RJ, et al. Early invasive versus conservative treatment strategies in women and men with unstable angina and non-ST-elevation myocardial infarction. JAMA. 2008;300:71-80.

51 Vaccarino V, Abramson JL, Veledar E, et al. Sex differences in hospital mortality after coronary artery bypass surgery: evidence for a higher mortality in younger women. Circulation. 2002;105:1176-81.

52 Alexander KP, Chen AY, Newby LK, et al. Sex differences in major bleeding with glycoprotein IIb/IIIa inhibitors: results from the CRUSADE initiative. Circulation. 2006;114:1380-7.

53 Berger JS, Bhatt DL, Cannon CP, Chen Z, Jiang L, Jones JB, et al. The relative efficacy and safety of clopidogrel in women and men. J Am Coll Cardiol. 2009;54:1935-45.

54 Phan A, Shufelt C, Bairey Merx NC. Persistent chest pain and no obstructive coronary artery disease. JAMA. 2009;301:146874 .

55 Gulati M, Cooper-DeHoff RM, McClure C, Johnson D, Shaw LJ, Handberg EM, et al. Adverse cardiovascular outcomes in women with nonobstructive coronary artery disease. A report from the Women's Ischemia Syndrome Evaluation Study and the St James Women take Heart Project. Arch Intern Med. 2009;169:843-50. 


\section{CVOI E-learning formula!}

This is the CVOI e-learning article. The author has prepared 10 questions which are available through the website of our Cardiovascular Educational Institute (CVOI). Please follow the instructions below.
Website:
www.cvoi.nl
Press button:
"toetsvragen"
Login:
NHJtoets12
Password:
011210

After finishing the questions you will be asked to fill in your name, hospital and e-mail address; then press the button "verzenden".

When 6 out of the 10 questions are answered correctly, you acquire 1 accreditation point granted by the Quality Committee of our Netherlands Society of Cardiology (NVVC). The acquired accreditation point will be credited in your personal file in the GAIA system. You will also receive an enclosure by e-mail with all the correct answers.

Please note that the questions of every article are available on the CVOI website for just one month until the publication of the next e-learning article (on the 10th of each month).

Over a period of one year 10 e-learning articles will appear in 10 subsequent NHJ editions. In every NHJ edition (except the July/ August edition) a special e-learning article will be published recognisable by a special icon. On an annual basis you can collect 10 accreditation points. The accreditation points are credited in the GAIA system by the CVOI.

If you need additional information, please contact the CVOI by mail: cvoi@cvoi.org or by phone: 030-2345001.

We invite all readers of the NHJ to actively take part in this new, instructive and stimulating way of e-learning.

\section{E.E. van der Wall}

Chief Editor

Netherlands Heart Journal 